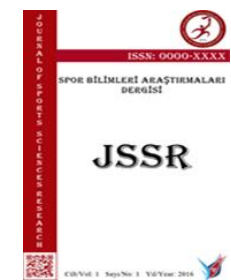

SPOR BİLIMLERİ ARAŞTIRMALARI DERGISİ

Journal of Sport Sciences Researches

http://dergipark.gov.tr/jssr

ISSN: 2548-0723

\title{
Theoretical Aspects of the Athletic Training for High-Skilled Players Development as Exemplified by Table Tennis
}

\author{
Mocrousov ELENA ${ }^{1^{*}}$ \\ ${ }^{1}$ University of Physical Education and Sports of The Republic of Moldova, https://orcid.org/0000-0002-4037- \\ 4037
}

\begin{abstract}
Problems of the athletic training, particularly those that refer to the most important and complex ones in the modern sport, require further insightful decision. So far the generalpurpose aspects of the athletic training have been largely developed. The basis for the theoretical generalization made the facts, results of observations and experimental studies, obtained mainly in sports with an objective evaluation of the results. General regularities of the Soviet system of athletic training have received a broad generalization in the research papers of Ozolin (1949), Matveev (2005), Vaitsekhovsky (1970), Nabatvikova (1982), Platonov (1987), and Filin (1980). At the same time, it remains unexplored, in particular, the extent to which the general aspects and patterns revealed in the sports theory are valid for the training of highly-skilled athletes in sports with a different evaluation of results, which include individual types of sports games. There are no experimental studies that reveal the fundamentals of construction of training of high-skilled athletes in individual sports, which makes it necessary to conduct them. When developing the concept of the fundamentals of construction of training of high-skilled athletes, the parameters of the competitive activity of the modern highly-skilled table tennis athletes will be determined on the example of table tennis; we shall introduce in the practice the idea of volume and structure of training and competitive loads of highly-skilled athletes; we shall explore functional changes caused by competitive loads of high-class tennis players and methodical approaches to the definition of the competition form, the models of the training facilities and load parameters in training spells, microcycles, mesocycles and macrocycles of training of high-skilled athletes taking into account the specifics of competitive activity on the basis of the general principles of athletic training.
\end{abstract}

Review

Article Info
Received: 08.09 .2018
Accepted: 19.11 .2018
Online Published: 31.12 .2018

DOI: $10.25307 /$ jssr.457570

\section{INTRODUCTION}

Athletic training is a managed by scientific, in particular, pedagogical principles, process of sports excellence enhancement, which (process) purpose consists in bringing an athlete to high results in any kind of sport, through sustained and systematic impact on his / her capabilities and proficiency. The purpose of sports training is to prepare athletes for the highest sports achievements. Practice of high performance sport shows that the regularities inherent in the training of rated athletes cannot be always used in the preparation of athletes of top qualification. Direct transfer of these regularities in the training process of the abovementioned category of athletes is fraught with many mistakes and, as a rule, is accompanied by a significant decline in results in international competitions.

\footnotetext{
*Corresponding Author: Mokrousov ELENA, Email: miss_sport_tabletennis@yahoo.co.uk
} 
Elena, M. (2018). Theoretical aspects of the athletic training for high-skilled players development as exemplified by table tennis. Spor Bilimleri Araştırmaları Dergisi, 3(2), 244-251.

Athletic training is characterized by regularity and consistency. This is in contrast with other factors that also affect the physical and athletic work capacity of a person. The regularity of athletic training is reflected in the training plans that being developed on a scientific basis and with consideration of best practices provide a systematic improvement of athletic work capacity (Bompa, 2003; Matveev, 1991; Platonov, 1987). Next, all the more brightly emanating distinguishing feature of the athletic training is its scientific character. If relatively recently especially talented athletes succeeded on the basis of the experience of individual coaches to achieve high sports results internationally, in our time such path has no future. Modern training in elite sport is based on public and natural-science knowledge. Besides, for theoretical saturation, and methodological training design the following is of great importance: sports psychology, sports medicine, biomechanics, biochemistry, sports science discipline, as well as management science, sociology, cybernetics, mathematics, neurophysiology, and etc. (Barchukova \& Baksheev, 2006; Ozolin, 1949). To provide the scientific character of training it is also necessary to be aware of the experience of the most successful coaches and athletes, generalize this experience and creatively use it in accordance with the specific conditions of the chosen kind of sport (Aksenov \& Gaskov, 2009; Kvashuk, 2003; Matveev, 2005; Mokrousov, 2012).

Table 1. Presents the Basic terms of athletic training with a brief explanation

\begin{tabular}{|c|c|c|}
\hline Term & Questions to be answered & Short answers \\
\hline Training objectives & $\begin{array}{l}\text { What must be achieved and/or } \\
\text { improved? }\end{array}$ & $\begin{array}{l}\text { General objectives } \\
\text { Training objectives } \\
\checkmark \text { Objectives of training exercises }\end{array}$ \\
\hline Training content & What should be done? & $\begin{array}{l}\text { Long-term plan of the training } \\
\text { process } \\
\text { Medium-term training plan } \\
\text { Short-term training plan } \\
\text { Exercises: }\end{array}$ \\
\hline Training facilities & $\begin{array}{l}\text { What exercises, equipment, and } \\
\text { auxiliaries should be involved? }\end{array}$ & $\begin{array}{l}\checkmark \text { competitive, specific for this } \\
\text { sport (special) and general- } \\
\text { preparatory; } \\
\checkmark \text { technical means of training; } \\
\checkmark \text { machines, devices and various } \\
\text { equipment. }\end{array}$ \\
\hline Training methods & What exercises should be performed? & $\begin{array}{l}\text { Continuous uniform Continuous } \\
\text { variable } \\
\text { Interval with the given rest } \\
\text { intervals } \\
\text { Interval with unlimited rest } \\
\text { intervals } \\
\text { Gaming }\end{array}$ \\
\hline
\end{tabular}

The content and orientation of the physical training of athletes of top qualification, as well as the ratio of its constituents (general and special physical training) in annual training macrocycle is one of the actual problems of the modern theory of sport (Matveev, 1964; Platonov, 2002; Platonov, Sakhnovsky \& Ozimec, 2003). Training macrocycle structure is subordinated primarily to the solution of the objectives of the athletic training on a specific stage of the long-term performance. Therefore, the construction of the training macrocycles at the first stage of the long-term development in which the main focus is made on the creation (on the basis of harmonic physical development and strengthening of general performance 
Elena, M. (2018). Theoretical aspects of the athletic training for high-skilled players development as exemplified by table tennis. Spor Bilimleri Araştırmaları Dergisi, 3(2), 244-251.

capability) of technical and functional prerequisites for efficient athlete development in the future, is fundamentally different from the construction of macrocycles focused on the maximum realization of personal capabilities (Filin, \& Fomin, 1980; Platonov, 2002; Platonov, Sakhnovsky \& Ozimec, 2003; Verkhoshansky, 1970). Therefore, at the first and second stages of the Olympic cycle, the training process is mainly based on the annual macrocycles, with which objectives of physical, psychological, technical and tactical athlete development (Platonov, 2004; Platonov, 1987) are being solved in parallel (and if necessary, sequentially).

Despite the fact that over the past 30 years a large number of publications appeared in press summarizing experience of physical training of skiers, swimmers, track athletes, gymnasts, wrestlers, rowers, weightlifters, gamers, figure skaters and representatives of other sports, there are many controversial issues, including balance between general physical preparedness (GPP) and specific physical preparedness (SPP). Mistakes in the determination of balance between GPP and SPP mean reduce the effectiveness of athletes' performances in international competitions. This is due primarily to the peculiarities of the chosen sport, regularities of the development of the main sportsmanship components, the necessity in athlete preparation for participation in specific competitions, individual adaptation capabilities of the athlete, level of his / her tactical and psychological preparation, content of previous macrocycle of the training process.

According to the literature data, modern athletic training is a complex dynamic process aimed at achieving a high-end result (Aksenov \& Gaskov, 2009; Platonov, 2004; Rubin, 2004). Currently, when determining the content of the "athletic training" term there are two approaches which do not contradict each other but have some differences consisted mainly in the definition of conditional borders of the studied issue.

In the first case the athletic training refers to the whole diverse process of training, part of which, in addition to the direct use of a variety of physical exercises with the purpose of sports excellence enhancement, is a complex of the actions directed on education of the athlete, improving his /her special and other knowledge that have an indirect importance for the growth of sports results level. Other experts understand the athletic training as a process of targeted use of pedagogical instruments for the development of qualities and skills that are critical in a particular sport and, therefore, influence the level of sports achievements in muscular activity that is defined as a subject of specialization.

In conformity with these two approaches to defining the content of the "athletic training" term, we may specify two approaches to the definition of "management of the athletic training" term. When determining the content of the management process Ozolin (1949) is considering a range of tasks related to learning, personal development and increasing of functional capabilities, i.e. the management process is largely identified with the process of education. In this case, the process of athletic perfection management is seen as a leading, but an integral part of management (Aksenov \& Gaskov, 2009; Kvashuk, 2003; Platonov, 1987). At the same time, according to widespread in recent years opinion, management is defined as the process of targeted transfer of the athlete's body state at a qualitatively new level that meets the increasing requirements for a specific sport, by using physical exercises that cause 
Elena, M. (2018). Theoretical aspects of the athletic training for high-skilled players development as exemplified by table tennis. Spor Bilimleri Araştırmaları Dergisi, 3(2), 244-251.

complex functional and psychological adaptive changes that determine the training level of the athlete. We have taken for the basis the second definition of the "management of the athletic training" term and the corresponding to it concept of the "athletic training" (Filin \& Fomin, 1980; Platonov, 2004; Platonov, Sakhnovsky \& Ozimec, 2003; Rubin, 2004).

Let us consider the opinions of the leading experts in the field of theory and methodology of the athletic training on the organization of effective management of the training process.

According to the opinion of Ozolin (1949), the training process management includes the following interrelated parts: identification of individual differences and functional capacity of the athletes; setting a goal and time needed to achieve it; definition of the specific objectives of learning, education and increasing the functional capacity level; selection of the means, methods, and load intensity; developing training plans; plan implementation and regulation of training and competitive effects in concordance with athlete's capabilities and level of his / her training (Matveev, 1964).

While considering the implementation of the idea of training process management from the standpoint of cybernetics, Verkhoshansky (1970) notes that management efficiency depends on the quality of operations on two interrelated control loops: motor load - training load potential - athlete's condition (loop A) and athlete's condition - training load effect - the athlete's external interactions (loop B). With that it is noted that the training program serves as a managing starting point.

Platonov (1987) associated the efficiency of the athletic training process management with the implementation of a number of key management operations: characterization of the structure of competitive activity and special performance; establishment and characterization of the model of training and competitive activities; diagnostics of individual functional capabilities of the athlete; comparison of individual and model data; identification of focus areas and ways to achieve a given effect; selection of means and methods of athlete training; planning of training process; phased comparison of actual and planned results; planning of corrective actions (Ozolin, 1949; Platonov, 1987; Platonov, 2004; Platonov, Sakhnovsky \& Ozimec, 2003).

Table 2. The Various types and examples of training loads interaction

\begin{tabular}{|c|c|c|}
\hline $\begin{array}{l}\text { Training Loads } \\
\text { Interaction }\end{array}$ & The essence of the interaction & Examples \\
\hline Positive summation & $\begin{array}{l}\text { Load is summarized with previous one } \\
\text { (similar in modality) and increases the } \\
\text { accumulated training effect }\end{array}$ & $\begin{array}{l}\text { A series of exercises with sufficient } \\
\text { intervals for recovery is planned to achieve } \\
\text { the accumulation of loads }\end{array}$ \\
\hline $\begin{array}{l}\text { Positive relief of } \\
\text { recovery }\end{array}$ & $\begin{array}{l}\text { Loading facilitates recovery from } \\
\text { previous trainings }\end{array}$ & $\begin{array}{l}\text { Low-load aerobic exercise improves } \\
\text { recovery after very intense weight training } \\
\text { or training for anaerobic endurance }\end{array}$ \\
\hline Neutral & $\begin{array}{l}\text { The previous load has no effect on } \\
\text { subsequent }\end{array}$ & $\begin{array}{l}\text { Subsequent training is performed after a } \\
\text { long recovery period; effect of the previous } \\
\text { load is limited }\end{array}$ \\
\hline $\begin{array}{l}\text { Negative excessive } \\
\text { load }\end{array}$ & $\begin{array}{l}\text { Subsequent load together with previous } \\
\text { ones causes excessive fatigue }\end{array}$ & $\begin{array}{l}\text { A series of heavy loads may induce chronic } \\
\text { fatigue; high motivation in performing this } \\
\text { series of trainings can lead to excessive } \\
\text { fatigue }\end{array}$ \\
\hline $\begin{array}{l}\text { Negative } \\
\text { deterioration of } \\
\text { reactions }\end{array}$ & $\begin{array}{l}\text { The subsequent load is not compatible } \\
\text { with the previous one; its impact affects } \\
\text { the athlete's reaction and his / her } \\
\text { adaptation process }\end{array}$ & $\begin{array}{l}\text { Endurance load to the point of } \\
\text { physical exhaustion impairs recovery after } \\
\text { previous training aimed at muscle } \\
\text { hypertrophy, reducing its effect }\end{array}$ \\
\hline
\end{tabular}


Elena, M. (2018). Theoretical aspects of the athletic training for high-skilled players development as exemplified by table tennis. Spor Bilimleri Araştırmaları Dergisi, 3(2), 244-251.

In general, according to the authors mentioned above, as well as several other experts in the field of theory and methodology of athlete training, management process is represented as follows: transfer of the subject of management, i.e. from current athlete's condition to the planned one, is connected first and foremost with clear quantitative characteristic of the controlled system, in other words, we are talking about characteristics of special proficiency structure, based on specifics and specific requirements of the sport, peculiarities of competitive activity. The direction of athlete performance is determined based on the comparison of indicators characterizing the structure of competitive activity and special proficiency with the corresponding model characteristics. Monitoring is carried out during the implementation of the training program and, if necessary, the corrective actions are planned.

Summarizing the data described herein, it should be noted that organization of the athletic training management process is based on characteristics of special proficiency structure by reference to specific features of competitive activity in a particular sport inasmuch as the main components of the management process control are subject to the task to achieve the optimal proficiency structure.

In Platonov's, (2004) judgement the proficiency concept reflects the whole range of athlete's abilities to demonstrate his / her maximal capabilities and high sports results in competitions. Besides training level proficiency also includes another components of sports excellence: theoretical knowledge, mental set to achieve maximum results, mobilization readiness to contest, etc.. (Ozolin, 1949; Platonov, 2004; Platonov, 1987).

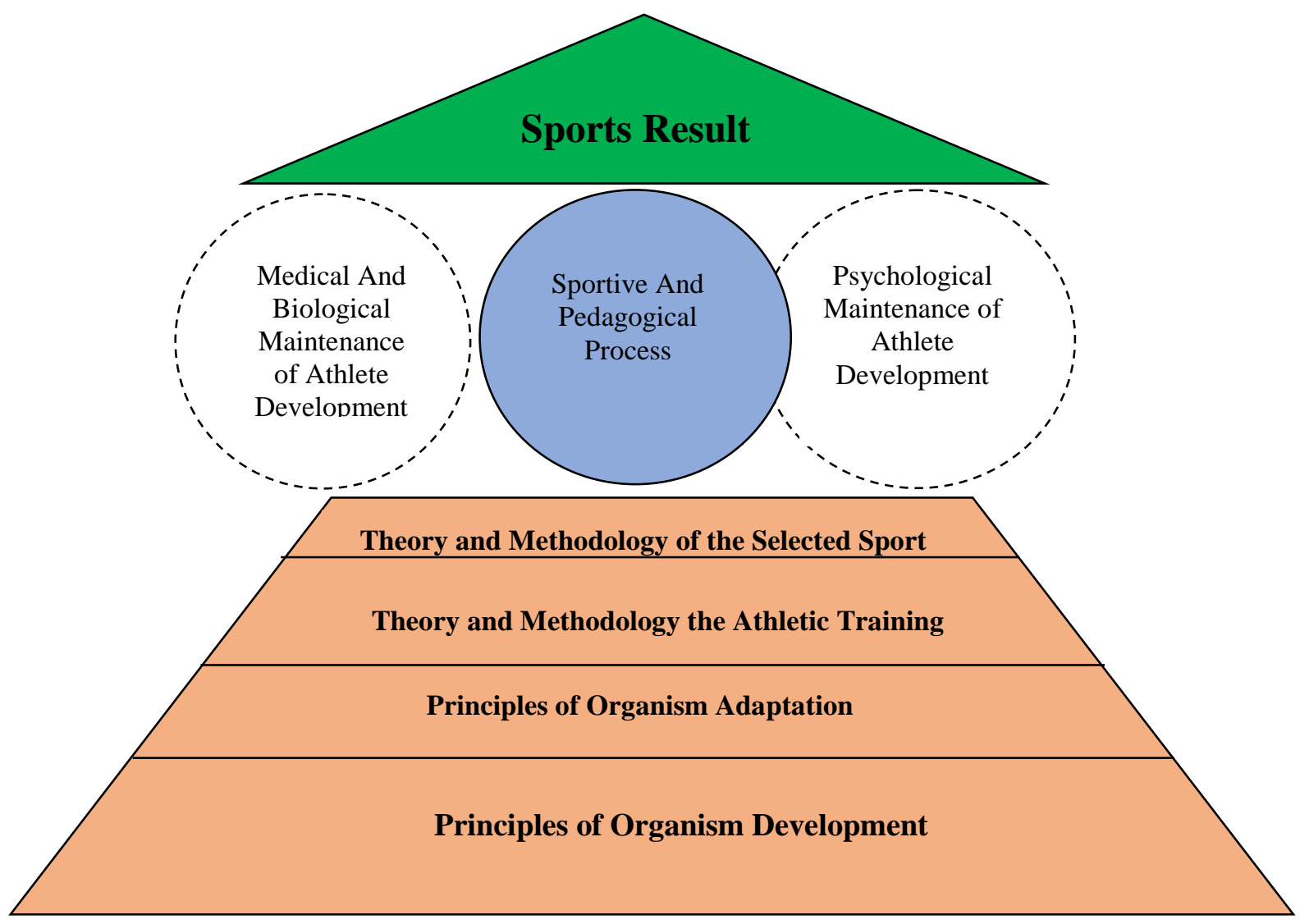

Figure 1. Sports development of an athlete 
Elena, M. (2018). Theoretical aspects of the athletic training for high-skilled players development as exemplified by table tennis. Spor Bilimleri Araştırmaları Dergisi, 3(2), 244-251.

Goal of research is to define the main regulations governing the construction of sports training of high-skilled athletes on the example of table tennis.

\section{Research objectives:}

1. Study of the competitive activities of Moldavian and foreign table tennis players during a long-term development process.

2. Study the training activities of highly- skilled tennis players, in particular, composition of training resources, distribution by the cycles of training, volume and intensity of exercises, training loads intensity and their dynamics in the micro, meso and macrocycles.

3. Identification, modeling and practical verification of the forms of training construction in the scale of micro, meso and macrocycles in the process of long-term development of highskilled athletes in table tennis.

The following main challenges arise in the process of training on the example of table tennis that needs to be considered and addressed in a comprehensive manner:

1. Physical training: The main content of physical training is to develop physical abilities, especially endurance, strength, speed and flexibility. These particular abilities, also collectively defined by the term "condition", constitute a decisive prerequisite for sport capacity. Physical training should be aimed primarily at the development of physical abilities that are typical for table tennis. To achieve the desired effect along with exercises that make up a program of competitions, the training must include various general-preparatory and special exercises.

2. Athletic, technical and tactical training: Rational technique ensures efficient and optimal utilization of physical abilities. In the process of sports and technical training, the athlete learns the technique and reinforces it in the specific conditions of competition. Progressively with development of strength, endurance, and speed, the athlete needs to increase the level of his / her technical preparedness. Therefore, both the physical and technical training are continuously and closely linked. Technical and tactical trainings in table tennis constitute unified whole. Technical skills serve as the basis for tactical actions. These skills need to be developed in terms of their applicability in certain tactical situations.

3. Intellectual preparation: Requirements to mental capacity in elite sport are growing continuously. Table tennis is an individual sport. The athlete needs to be highly self-acting in training, be able to implement tactical combinations in the competitions with the everincreasing level and density of the results. He/she should also actively develop sports technique and be able to use it in training, etc. All this require from an athlete constant improving his / her knowledge in all areas of the theory of sports and learning of their creative appliance in training and competition. Therefore, intellectual education and personal development should be an integral part of the training in table tennis. 
Elena, M. (2018). Theoretical aspects of the athletic training for high-skilled players development as exemplified by table tennis. Spor Bilimleri Araştırmaları Dergisi, 3(2), 244-251.

\section{CONCLUSIONS}

The development of theory and methodology of the athletic training in historical terms is inextricably linked with the increasing social functions of sport in modern society. Retrospective analysis of preparation and participation of the world sports elite in the Olympic, World, European and other major competitions shows that modern achievements in sport are the end result of the combined intellectual and physical energy of a wide range of experts, materialized in the training process. Consequently, the intellectualization of the athletic training is a central and dominant factor of sports achievements in the modern system of the athletic development.

Commercialization of sports offers athletes a variety of material and moral incentives that guide their actions in selective participation in various sporting competitions; theoretical and practical experience gained in studying mechanisms of adaptive process (mainly in the medico-biological and psychological terms) helps in finding effective means and methods of sustainable maintenance of training level and on this basis - more flexible forms to pick the required form or temporary lose it; professionalisation of training and competitive activity has made a number of adjustments in the sports regimen of athletes, respectively, in the structure and content of the macro, meso, and micro-cycles (especially in the latter). As a result, there is a clear differentiation of the athletic training planning and management, depending on the specifics of each sport. Restoration system in modern athletic training should be built on a strictly scientific basis, taking into account the laws and mechanisms of the adaptation process. It is necessary to widely apply the sportive, pedagogical, psychological means and medications in frames of so-called restorative, tonic and competitive microcycles.

In the training process, it is necessary to achieve high volumes of training loads and a rational combination of trainings with different intensity modes with a focus on the specifics of the competition and the result. To take into account the balance between training and competition loads, rest, special restoration means, specialized nutrition and work capacity simulation aids.

\section{REFERENCES}

Aksenov, M.O., \& Gaskov, A.V. (2009). Principles of athlete training. Ulan-Ude: Published by Buryat State University, p.80. [In Russian]

Barchukova, G., Baksheev, K. (2006) Problems evaluation and planning of loadings in sports (on the tennis example). The Theory and Practice of Physical Culture, № 9, p.32-36. [In Russian]

Bompa, T. (2003). Young champion training. Journal “Astreli”, pp.260. [In Russian]

Filin V.P., Fomin N.A. (1980) Fundamentals of youth sports. Physical culture and sport, 255 pp. [In Russian]

Kvashuk, P.V. (2003). Differentiated approach to the construction of the training process of the young sportsmen at the stages of long-term development. Sports Science Bulletin, No. 1, pp.32-35. [In Russian]

Matveev, L. P. (1964). Problem of athletic training periodization. Physical culture and sport, scientific theoretical journal $n r .8$, pp.54-64. [In Russian] 
Elena, M. (2018). Theoretical aspects of the athletic training for high-skilled players development as exemplified by table tennis. Spor Bilimleri Araştırmaları Dergisi, 3(2), 244-251.

Matveev, L.P. (1991). Theory and methodology of physical culture (General basics of theory and methodology of physical education; theoretical and methodological aspects of sports and professional and applied forms of physical culture): textbook for institutes of physical culture. Moscow: Physical culture and sport, pp.543. [In Russian]

Matveev, L.P. (2005). General theory of sport and its applied aspects. Scientific Journal "Lani” 4th ed., pp.45-50. [In Russian]

Mokrousov, E. (2012). Regarding the issue of training the technique of playing table tennis. In: Materials of International Scientific Conference of PhD Students' "Physical Culture: Scientific problems of Education and Sport ". $8^{\text {th }}$ Edition. Chisinau SUPES, 234-238 p. [In Russian]

Nabatnikova, M.I. (1982). On the content of training young athletes. Scientific and sports bulletin, nr. 1, pp.6 - 9. [In Russian]

Ozolin, N. G. (1949). Track athlete training. Physical culture and sport, pp.48-52. [In Russian]

Platonov, V. (2004). System of athlete training in Olympic sports. In General theory and its practical applications. Kiev: Olympic literature. Kiev, p. 802. [In Russian]

Platonov, V., Sakhnovsky, K., Ozimec, M. (2003). Modern strategy of long-term athlete development. Science in Olympic sports, No. 1, pp. 3-13. [In Russian]

Platonov V.P. (ed.) (1987). Theory of sports. Kiev: Vishcha Shkola, pp.424. [In Russian]

Platonov, V.P. (2002). Encyclopedia of the Olympic sports: in 5 volumes / under the general editorship. Kiev: Olympic literature, pp.494. [In Russian]

Rubin, V.S. (2004). Olympic and annual training cycles. In Theory and practice: study guide. Moscow: Sovetsky sport, 136 pp. [In Russian].

Vaitsekhovsky, S.M. (1970). Manage your workout process, Coach book. Journal Physical education and sport, pp.24-28. (In Russian).

Verkhoshansky, Y.V. (1970). Regularities of functional specialization of the organism in the course of the sports skills formation. Theory and practices of physical culture, No. 6. pp. 10-13. [In Russian] 